\title{
A polymeric colchicinoid prodrug with reduced toxicity and improved efficacy for vascular disruption in cancer therapy
}

This article was published in the following Dove Press journal:

International Journal of Nanomedicine

| November 201 |

Number of times this article has been viewed

\section{Bart J Crielaard' \\ Steffen van der Wal' \\ Twan Lammers ${ }^{2}$ \\ Huong Thu Le' \\ Wim E Hennink' \\ Raymond M Schiffelers' \\ Gert Storm \\ Marcel HAM Fens' \\ 'Department of Pharmaceutics, Utrecht Institute for Pharmaceutical Sciences, Utrecht University, Utrecht, The Netherlands; ${ }^{2}$ Department of Experimental Molecular Imaging, RWTH Aachen University, Aachen, Germany}

The first two authors contributed equally to this work.
Correspondence: Gert Storm Department of Pharmaceutics, Utrecht Institute for Pharmaceutical Sciences, Utrecht University, PO Box 80082, 3508 TB Utrecht, The Netherlands $\mathrm{Tel}+3$ I 302537388

Fax $+3|3025| 7839$

Email g.storm@uu.nl

\begin{abstract}
Colchicinoids are very potent tubulin-binding compounds, which interfere with microtubule formation, giving them strong cytotoxic properties, such as cell mitosis inhibition and induction of microcytoskeleton depolymerization. While this makes them promising vascular disrupting agents (VDAs) in cancer therapy, their dose-limiting toxicity has prevented any clinical application for this purpose. Therefore, colchicinoids are considered attractive lead molecules for the development of novel vascular disrupting nanomedicine. In a previous study, a polymeric colchicinoid prodrug that showed favorable hydrolysis characteristics at physiological conditions was developed. In the current study, this polymeric colchicinoid prodrug was evaluated in vitro and in vivo for its toxicity and vascular disrupting potential. Cell viability studies with human umbilical vein endothelial cells, as an in vitro measure for colchicine activity, reflected the degradation kinetics of the prodrug accordingly. Upon intravenous treatment, in vivo, of B16F10 melanoma-bearing mice with colchicine or with the polymeric colchicinoid prodrug, apparent vascular disruption and consequent tumor necrosis was observed for the prodrug but not for free colchicine at an equivalent dose. Moreover, a five-times-higher dose of the prodrug was well tolerated, indicating reduced toxicity. These findings demonstrate that the polymeric colchicinoid prodrug has a substantially improved efficacy/toxicity ratio compared with that of colchicine, making it a promising VDA for cancer therapy.
\end{abstract}

Keywords: colchicine, prodrug, nanomedicines, cancer, vascular disrupting agents

\section{Introduction}

The extract of Colchicum autumnale, which is more commonly known as autumn crocus, wild saffron, naked lady, or any of several other names, has been used in the therapy of gout for more than 15 centuries. ${ }^{1}$ At present, it is still in clinical use for the treatment of gout, as well as several other inflammatory diseases including familial Mediterranean fever and Behçet's disease. ${ }^{2,3}$ Colchicine and its colchicinoid derivatives possess the ability to bind irreversibly to tubulin, forming tubulin-colchicine complexes, which hinder microtubule formation and inhibit cell mitosis. ${ }^{2-4}$ It has been described that colchicine possesses anti-inflammatory properties, mainly mediated by inhibition of leukocyte adhesion and activity. ${ }^{2,5}$ At higher doses, tubulin-colchicine complexes induce depolymerization of microtubules, resulting in destabilization of the tubulin cytoskeleton. ${ }^{4,6,7}$ Whereas most cells rely on actin for their cell morphology, endothelial cells of angiogenic tumor vasculature are more dependent on tubulin to maintain their typically enlongated shape. ${ }^{6,8}$ Therefore, upon colchicinoidinduced microtubule depolymerization, the tumor endothelial cells lose their shape, thereby exposing the vascular basement membrane, which subsequently leads to 
coagulation, decreased perfusion, and hemostasis..$^{9,10}$ This process, known as vascular disruption, deprives the surrounding (tumor) cells of oxygen and nutrients, leading to massive tissue necrosis. Currently, however, there is no use for colchicine and colchicinoids in cancer therapy due to their high systemic toxicity. ${ }^{11}$ Although in preclinical cancer models doses of colchicine higher than $5 \mathrm{mg} / \mathrm{kg}$ induce a significant reduction in the perfusion of tumors, the maximum tolerated dose (MTD) of colchicine is limited to around $1 \mathrm{mg} / \mathrm{kg} .{ }^{12,13}$ Even doses below $0.5 \mathrm{mg} / \mathrm{kg}$, as used in the clinical management of gout and familial Mediterranean fever, are frequently accompanied by gastrointestinal comorbidity (eg, nausea, vomiting, and diarrhea) and hematologic disorders, such as thrombocytopenia. ${ }^{14}$ Colchicine doses higher than $0.5 \mathrm{mg} / \mathrm{kg}$ are generally considered toxic, although lower doses may still cause significant side effects, illustrating its narrow therapeutic index. Overdosing of colchicine may eventually lead to multiple organ failure, including bone marrow suppression, hemolysis, liver failure, renal failure, convulsions, and cardiac arrest, and is often lethal. ${ }^{14,15}$

One strategy to limit the side effects caused by colchicinoid therapy is to design colchicinoid prodrugs, which possess pharmacological activity only upon conversion. ${ }^{16}$ Colchicinoids have a partition coefficient $(\log \mathrm{P})$ of around 1 and a relatively high volume of distribution $( \pm 2 \mathrm{~L} / \mathrm{kg})$, which implies that upon intravenous injection they immediately redistribute into the tissues, explaining the high risk for side effects. ${ }^{17-19}$ Therefore, by creating a colchicinoid prodrug with improved aqueous solubility, its volume of distribution is expected to be reduced, confining its distribution to the circulation and extracellular compartment and lowering its off-target toxicity. Additionally, to keep the prodrug in the proximity of its target cells, that is, the angiogenic endothelial cells, the tissue penetration of the prodrug may be reduced by increasing its molecular weight. Previously, colchicinoid prodrugs based on glycopeptide dendrimers and cobalamin (vitamin B12) have been synthesized and characterized in vitro. ${ }^{20,21}$ However, to be converted to the active colchicinoid, both conjugates required cellular uptake in the tumor tissue. For exploiting the direct cytotoxic activity of colchicinoids - the inhibition of tumor cell mitosis - this is a rational approach. For colchicinoid-induced vascular disruption, however, a colchicinoid prodrug that is converted extracellularly, preferably in the proximity of the tumor vascular endothelium, is needed. This may be achieved by utilizing polymer-based colchicinoid prodrugs that are more readily transformed into the active colchicinoid, such as by hydrolysis of an ester bond which allows conversion in aqueous conditions. Previous work reported the synthesis of a hydrophilic colchicinoid prodrug, where colchicine was derivatized and conjugated to poly(ethylene glycol) (PEG) using a linker liable to hydrolysis. ${ }^{22}$ The synthesis of nanomedicines by conjugating PEG-chains (PEGylation) to low-molecular-weight drugs increases the hydrophilicity and size of the construct, and shields them from interactions with plasma proteins. ${ }^{23-25}$ Upon intravenous injection, instantaneous and random diffusion of the colchicinoid prodrug into cells is impeded by the relatively large PEG moiety, thereby preventing the binding to tubulin and limiting its toxicity. However, due to the enhanced permeability of the imperfect angiogenic vasculature, the nanosized colchicinoid prodrug may be passively targeted to the tumor tissue, where, promoted by the reductive microenvironment in the tumor tissue, it hydrolyzes to the active colchicinoid. ${ }^{26}$ In the present study, a polymeric colchicinoid prodrug containing a hydrolysable linker was studied in vitro and in vivo for its therapeutic potential and toxicity as vascular disrupting agent.

\section{Materials and methods Synthesis of polymeric colchicinoid prodrug}

Colchicine was derived and conjugated to $\mathrm{PEG}_{5000}$ using methodology reported elsewhere (Figure 1). ${ }^{22}$ In brief, colchicine was hydroxyl-functionalized by substituting the $\mathrm{N}$-acetyl moiety with an N-2-hydroxyacetyl moiety. Subsequently, the hydroxyl group was reacted with methoxy PEG-acetic acid to obtain the hydrolysable polymeric colchicinoid prodrug. The amount of colchicine derivative per milligram of material (ie, colchicine equivalents) was determined by means of ultra performance liquid chromatography (UPLC) using an Acquity UPLC ${ }^{\circledR}$ BEH C18 $1.7 \mu \mathrm{m}$ column (Waters, Milford, MA) and ultraviolet detection at $350 \mathrm{~nm}$ (Acquity UPLC ${ }^{\circledR}$ PDA; Waters). The mobile phase consisted of a gradient from $5 \%-95 \%$ methanol in water $(\mathrm{v} / \mathrm{v})$ and trifluoroacetic acid as modifier.

\section{In vitro hydrolysis study}

The hydrolysis kinetics of the colchicinoid prodrug were determined at $4^{\circ} \mathrm{C}$ and $37^{\circ} \mathrm{C}$ in phosphate buffer $(20 \mathrm{mM}$, $\mathrm{pH}$ 7.4). During 72 hours, samples were taken at regular time intervals, and stored at $-20^{\circ} \mathrm{C}$ before analysis. For each time point, the concentration of colchicinoid prodrug and hydrolyzed prodrug were determined by UPLC, using the methodology described in the previous section. 
<smiles>COc1cc2c(c(OC)c1OC)-c1ccc(OC)c(=O)cc1[C@@H](NC(C)=O)CC2</smiles>

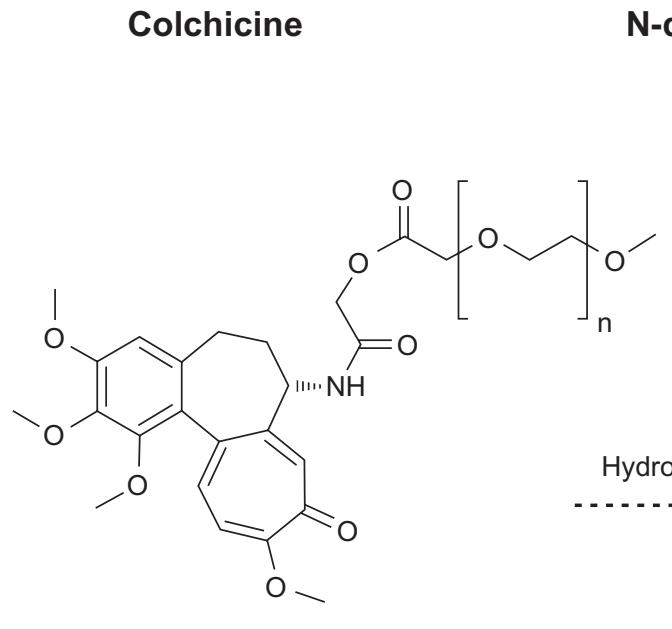

Colchicinoid prodrug
$\mathrm{N}$-deacetylcolchicine
Colchifoline

Hydrolysis $\mathrm{pH} 7.4$

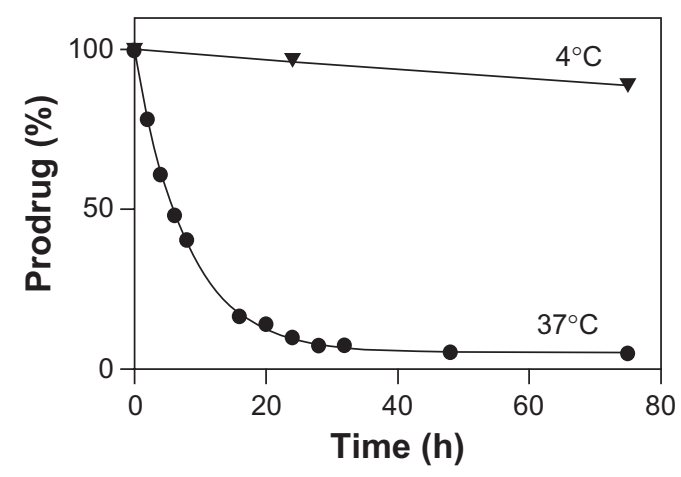

Figure I Synthesis and hydrolysis kinetics of colchicinoid prodrug. The synthesis of the colchicinoid prodrug is performed in three steps: (I) colchicine is deacetylated to obtain N-deacetylcolchicine; (2) N-deacetylcolchicine is acylated with glycolic acid resulting in a hydroxyl functionalized colchicinoid also known as colchifoline; and (3) the colchicinoid is coupled to methoxy $\mathrm{PEG}_{5000}$ to form the colchicinoid prodrug. By using esterification to conjugate PEG to the colchicinoid, a prodrug that is hydrolysable at physiological conditions is created: at $37^{\circ} \mathrm{C}$, the prodrug is cleaved within a day ( $\mathrm{t}_{1 / 2} 5.4$ hours), while at $4^{\circ} \mathrm{C}$ the hydrolysis rate is limited (calculated $\mathrm{t}_{1 / 2} 14$ days [zero-order kinetics]).

\section{In vitro cytotoxicity}

Human umbilical vein endothelial cells (HUVECs) were grown at $37^{\circ} \mathrm{C}$ and $5 \%$ carbon dioxide in angiogenic growth factor rich $\mathrm{EGM}^{\circledR}$-2 medium (Lonza Ltd, Basel, Switzerland). Cells were seeded in 96 -well plates $\left(1 \times 10^{4}\right.$ cells/well $)$ for 24 hours before further treatment. Subsequently, the cells were incubated with colchicine and colchicinoid prodrug at concentrations ranging from $0.025-2.5 \mu \mathrm{M}$ colchicine equivalents. The cytotoxicity of each drug after 6 hours, 24 hours, and 48 hours incubation was determined by colorimetric XTT (2,3-bis-(2-methoxy-4-nitro-5-sulfophenyl)$2 \mathrm{H}$-tetrazolium-5-carboxanilide) cell viability assay. ${ }^{27}$

\section{In vivo vascular disrupting efficacy of colchicinoid prodrug}

All animal experiments were conducted in agreement with the local applicable Dutch law, "Wet op de dierproeven" (1977), ${ }^{28}$ and the European Convention for the Protection of Vertebrate
Animals used for Experimental and Other Scientific Purposes (1986). ${ }^{29}$ The mice were housed in steel cages, and water and food were provided ad libitum. Female pathogen-free C57BL/6 inbred mice of 21-24 g (Charles River Laboratories International, Inc, Wilmington, MA) were subcutaneously inoculated with $1 \times 10^{6} \mathrm{~B} 16 \mathrm{~F} 10$ cells. Ten days after tumor cell inoculation, when tumor size reached $>100 \mathrm{~mm}^{3}$, phosphate buffered saline, colchicine $(1 \mathrm{mg} / \mathrm{kg})$, and the colchicinoid prodrug (1 mg/kg and $5 \mathrm{mg} / \mathrm{kg}$, colchicine equivalents) were administered intravenously in the tail vein. The mice were sacrificed at 4 and 24 hours after injection. The tumors were excised, snap frozen in liquid nitrogen, and stored at $-80^{\circ} \mathrm{C}$ upon sectioning.

\section{Histological evaluation}

Frozen tumor samples ( $\mathrm{n}=3$ per group) were sectioned $(5 \mu \mathrm{m})$, acetone fixed, and hematoxylin and eosin stained. Images were taken with an inverted microscope (Nikon Eclipse TE2000U; Nikon Corporation, Tokyo, Japan) using 
NIS Elements software (Nikon Corporation). Small magnification $(10 \times)$ overlapping images were taken of the complete tumor area and subsequently stitched together with PhotoFit (v 1.4; Tekmate, Inc, Anchorage, AK) software.

\section{Results and discussion}

Although colchicine is widely recognized as a promising VDA for cancer therapy, its dose-limiting toxicity has prevented it from realising this potential. ${ }^{11}$ Only by dosing colchicine well above its MTD, could significant vascular disruption and subsequent necrosis of tumor tissue be observed. ${ }^{12,13}$ In the present study, a PEG-based polymeric nanomedicine of colchicine was synthesized to attenuate systemic toxicity and to enhance its therapeutic index by improving its aqueous solubility. To this end, colchicine was derived and conjugated to $\mathrm{PEG}_{5000}$ via a hydrolysable linker (Figure 1). The molecular structure of colchicine was modified at the acetamido moiety, which is not part of the pharmacophore, creating a colchicinoid also known as colchifoline, with similar anti-inflammatory and tubulin-binding activity. ${ }^{7,30,31}$ Hydrolysis studies at physiological conditions $\left(37^{\circ} \mathrm{C}, \mathrm{pH} 7.4\right)$ showed that the half-life of prodrug conversion was approximately 5 hours, whereas, this was calculated by zero-order extrapolation at approximately 14 days at low temperature (Figure 1). The conversion rate of the prodrug at physiological conditions correlated with its activity in endothelial cell viability experiments. To investigate the antimitotic tubulin-binding capacity as a measure of efficacy, colchicine and the colchicinoid prodrug were incubated at different concentrations (0.025-2.5 $\mu \mathrm{M}$, colchicine equivalent) with primary HUVECs (Figure 2). After 6 hours of incubation, few or no apparent effects on cell viability were measured for each treatment (two-way analysis of variance, $P>0.05$ ), indicating that several hours of incubation are needed to allow colchicine to interfere with tubulin dynamics. However, after 24 hours and 48 hours of incubation, HUVEC viability was markedly decreased for both colchicine (dose $\geq 0.025 \mu \mathrm{M}, P<0.001$ ) and the polymeric colchicinoid prodrug (dose $\geq 0.125 \mu \mathrm{M}, P<0.001)$. The prodrug, of which $>95 \%$ is converted after 24 hours at $37^{\circ} \mathrm{C}$, showed at the highest doses a similar cytotoxicity in comparison with colchicine. However, at lower concentrations the prodrug was less potent than colchicine after 24 hours and 48 hours incubation $(P<0.05,0.125-$ $0.25 \mu \mathrm{M}$ at 24 hours; $0.025-0.25 \mu \mathrm{M}$ at 48 hours), despite the fact that practically all prodrug has been converted at these time points. The lower activity of the prodrug can be
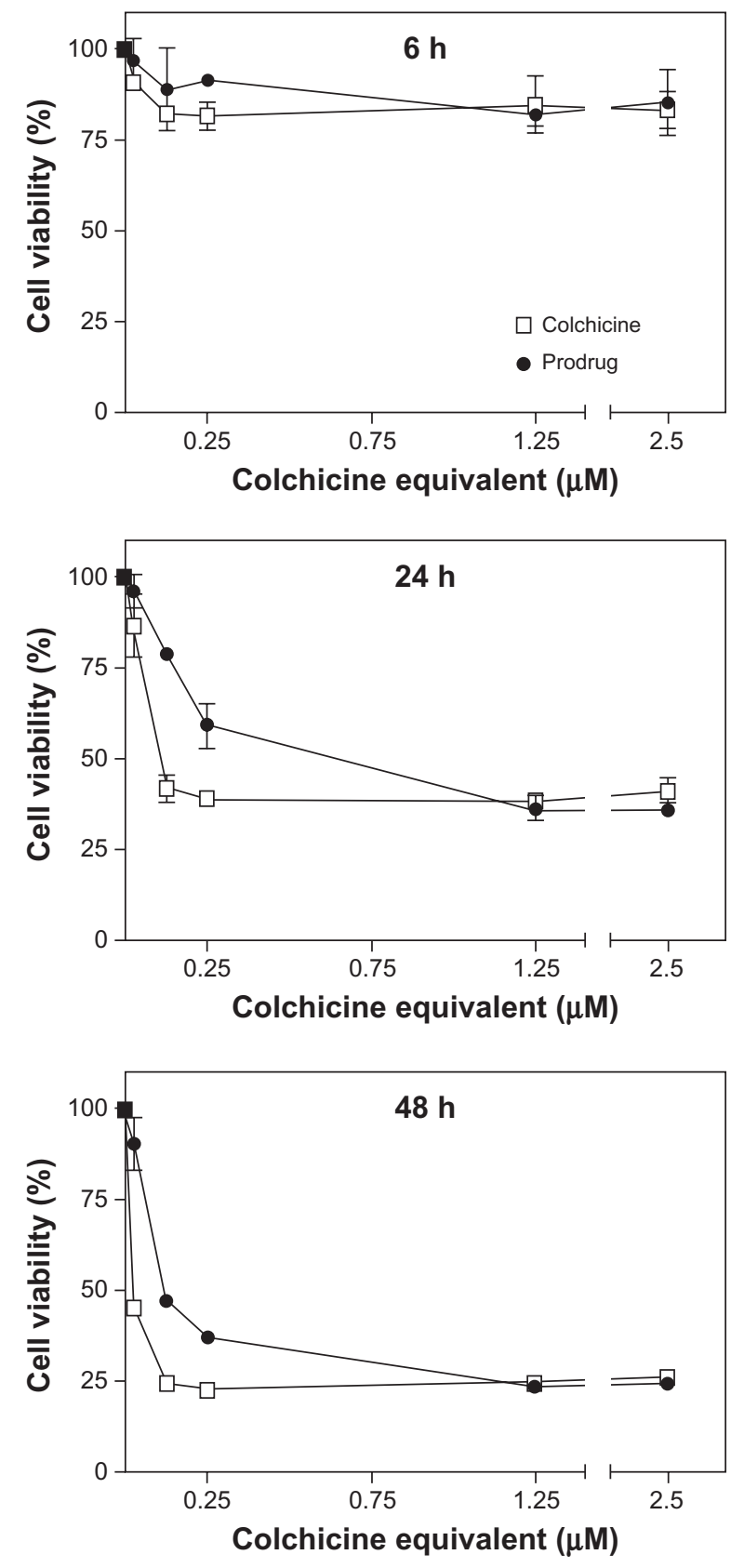

Figure 2 In vitro cytotoxicity of colchicine and colchicinoid prodrug. The endothelial cell toxicity of colchicine and the colchicinoid prodrug were determined as a measure of their ability to induce damage to angiogenic vasculature. Human umbilical vein endothelial cells were incubated with colchicine and colchicinoid prodrug at different equivalent concentrations during 6 hours, 24 hours, and 48 hours. Subsequently, the cell viability in respect to the untreated cells was determined by XTT assay. Whereas there was only low reduction in cell viability and no difference between the treatments after 6 hours of incubation, the colchicinoid prodrug was less cytotoxic than colchicine at 24 hours $(0.125 \mu \mathrm{M}$ and $0.25 \mu \mathrm{M}, P<0.05$, twoway analysis of variance) and 48 hours $(0.025-0.25 \mu \mathrm{M}, P<0.05)$.

explained by the delayed availability of the colchicinoid due to the time needed for conversion of the prodrug.

The in vivo efficacy and toxicity of colchicine and the colchicinoid prodrug as VDAs in solid tumors were assessed in mice bearing subcutaneous B16F10 melanoma tumors. 


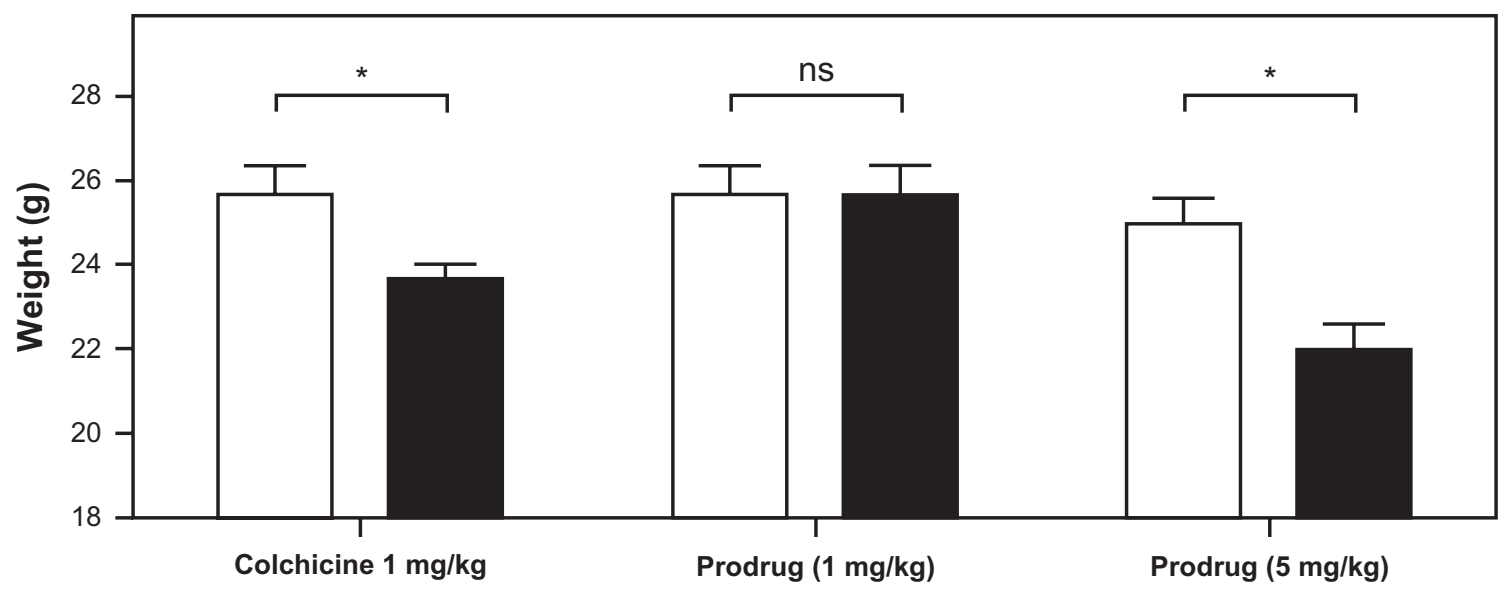

Figure 3 Effect of in vivo toxicity of colchicine and colchicinoid prodrug on the body weight of mice. To study their in vivo toxicity, colchicine ( $\mathrm{I}$ mg/kg) and the colchicinoid prodrug ( $1 \mathrm{mg} / \mathrm{kg}$ and $5 \mathrm{mg} / \mathrm{kg}$ colchicine equivalents) were intravenously injected into BI6FI0 melanoma-bearing mice. The weight of the mice was measured upon injection (0 hours, white bars) and 24 hours (black bars) after injection.

Notes: Significant weight loss was observed for mice treated with I mg/kg colchicine $(7.7 \%, P=0.037 \mathrm{I}$, one-tailed paired $t$-test) and $5 \mathrm{mg} / \mathrm{kg}$ colchicinoid prodrug (I2.0\%, $P=0.0175)$ (indicated by $*$ ), but not for mice treated with I $\mathrm{mg} / \mathrm{kg}$ colchicinoid prodrug $(0 \%, P>0.05)$ (indicated by NS).

To study the systemic toxicity, the weight of the mice was determined before and 24 hours after intravenous treatment with either colchicine or the prodrug. Approximately 8\% of total body weight was lost 24 hours after administration of $1 \mathrm{mg} / \mathrm{kg}$ colchicine $(P<0.05$ one-tailed paired $t$-test) (Figure 3). The high loss of body weight at 24 hours after treatment with $1 \mathrm{mg} / \mathrm{kg}$ colchicine illustrates the high toxicity of colchicine, which limits the maximum dose to a level considered insufficient to result in VDA activity. ${ }^{13}$ However, at $1 \mathrm{mg} / \mathrm{kg}$ colchicine equivalent dose, the polymeric prodrug did not induce significant weight loss, and only upon administration of a $5 \times$ higher dose $(5 \mathrm{mg} / \mathrm{kg})$, did it cause a drop in average body weight similar to that of colchicine at its MTD $(12 \%, P<0.05)$. This much higher tolerability of the prodrug compared with free colchicine may therefore allow for colchicinoid doses more likely to result in vascular disrupting activity.

The mice were sacrificed at 4 and 24 hours after treatment and the tumors were excised, sectioned, and stained to examine vascular disruption-induced tissue necrosis. No tumor necrosis was observed at 4 hours (Figure 4A and B) or 24 hours (data not shown) after intravenous injection of phosphate buffered saline or colchicine dosed at its MTD $(1 \mathrm{mg} / \mathrm{kg})$. The polymeric colchicinoid prodrug, however, induced tissue necrosis in multiple areas in the tumors 4 hours after administration at colchicine equivalent doses of $1 \mathrm{mg} / \mathrm{kg}$ and $5 \mathrm{mg} / \mathrm{kg}$ (Figure $4 \mathrm{C}$ and D, respectively). A similar extent of necrosis (approximately $50 \%$ of total tumor mass) was seen after 24 hours in the tumors of mice treated with colchicine equivalents of $1 \mathrm{mg} / \mathrm{kg}$ or $5 \mathrm{mg} / \mathrm{kg}$ of colchicinoid prodrug (Figure 4E and F). Although it has been shown previously for colchicine that intravenous doses of $5 \mathrm{mg} / \mathrm{kg}$ or higher are required to induce observable vascular disruption and subsequent necrosis in solid tumors, ${ }^{12,13}$ the polymeric colchicinoid prodrug exhibited vascular disrupting efficacy at a much lower dose $(1 \mathrm{mg} / \mathrm{kg})$, despite its reduced potency in vitro.

Polymer conjugation is a successful strategy in prodrug development that has been employed regularly for improving the aqueous solubility of the parent compound. ${ }^{25}$ An improved aqueous solubility changes the tissue distribution, which might explain the potency of the colchicinoid prodrug in relation to colchicine. ${ }^{16}$ By employing a PEG-chain larger than $35 \mathrm{kDa}$, or by utilizing colloidal drug delivery systems such as liposomes, a significant decrease in plasma clearance of the colchicinoid prodrug may be achieved, potentially enhancing its in vivo efficacy even more..$^{25,32,33}$ Nevertheless, the vascular disrupting efficacy at a low, nontoxic dose makes the polymeric colchicinoid prodrug presented here a promising VDA for cancer therapy. The observed favorable characteristics of the prodrug in vivo, on one hand, may be related to enhanced accumulation of the prodrug in the tumor tissue mediated by its improved aqueous solubility, limiting its distribution into other tissues and allowing it to penetrate via the "leaky" immature tumor vasculature. ${ }^{34}$ On the other hand, the increased expression and activity of reductive enzymes, such as esterases and carboxylesterases, in tumor and endothelial cells may augment tumor-specific conversion of the prodrug into the active colchicinoid, and thus improve its efficacy at the target site, while the polymer conjugation, as such, limits its toxicity toward other healthy tissues. ${ }^{26,35-39}$ 

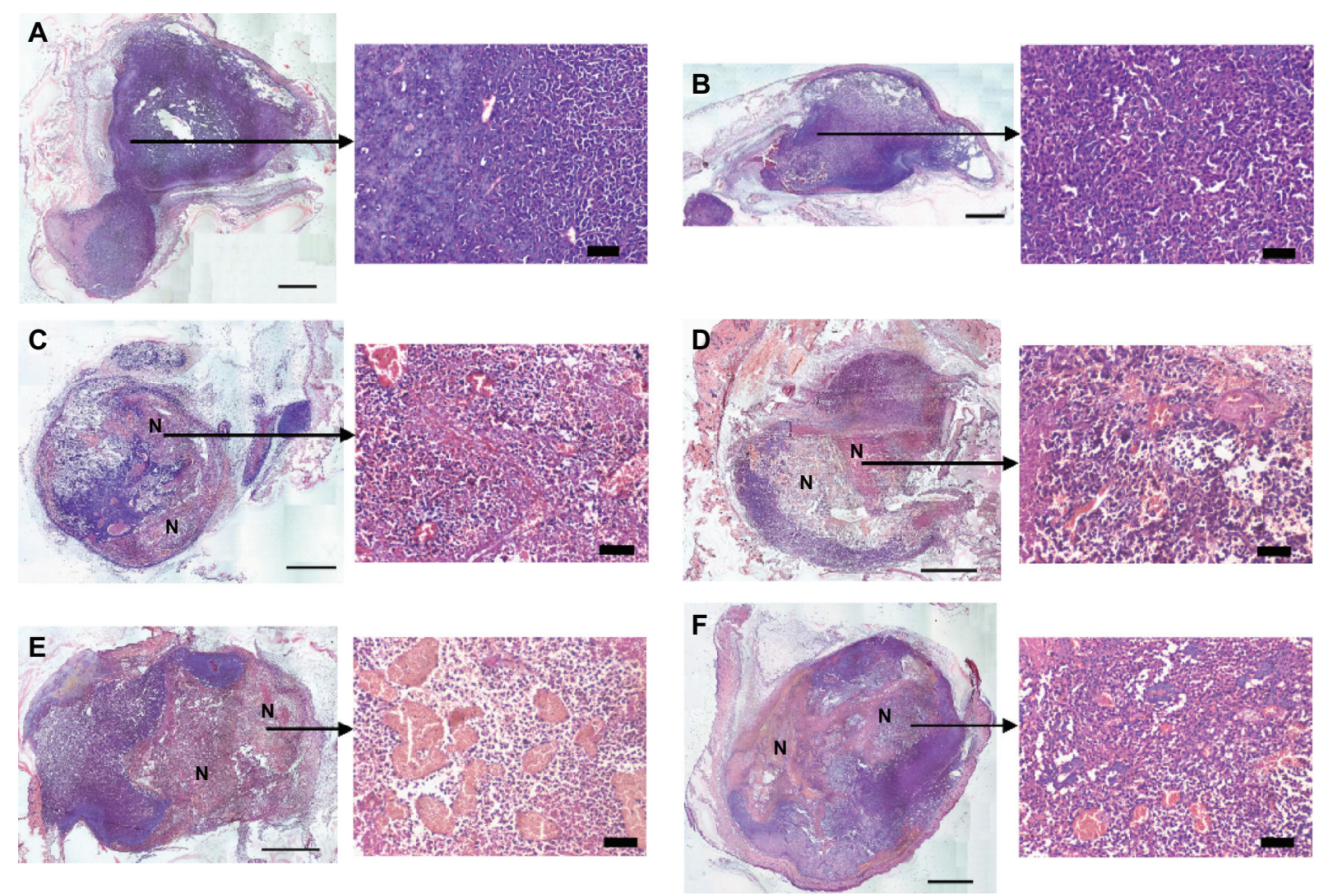

Figure 4 In vivo vascular disrupting activity of colchicine and colchicinoid prodrug. To investigate the vascular disrupting activity of colchicine and the colchicinoid prodrug, BI6FIO melanoma-bearing mice were treated with phosphate buffered saline, colchicine ( $\mathrm{l} \mathrm{mg} / \mathrm{kg}$ ), and colchicinoid prodrug (I mg/kg and $5 \mathrm{mg} / \mathrm{kg}$ ). The vascular disrupting activity of each treatment was evaluated by histological assessment of tumor tissue necrosis. Phosphate buffered saline-treated tumors did not show necrosis levels above background (A). Four hours after injection of I mg/kg colchicine tumor sections did not show tumor necrosis levels above control (B). Four hours after injection of I mg/kg (C) or $5 \mathrm{mg} / \mathrm{kg}$ (D) of colchicinoid prodrug, areas with congested blood vessels and necrotic cells were observed (as marked by N). Both I mg/kg (E) and $5 \mathrm{mg} / \mathrm{kg}(\mathbf{F})$ of the prodrug revealed considerable tumor necrosis 24 hours after injection (as marked by $\mathrm{N}$ ).

Note: Scale bars of overview images: I mm; magnifications: $50 \mu \mathrm{m}$.

\section{Conclusion}

The vascular disrupting efficacy and toxicity of a hydrolysable polymeric colchicinoid prodrug was studied in vitro and in vivo. The presented data convincingly demonstrate that the rate of hydrolysis of the prodrug at physiological conditions correlates with its reduced in vitro efficacy compared with colchicine. In vivo, the colchicinoid prodrug was found to be less toxic, while showing higher VDA efficacy than the parent compound, colchicine. Taken together, this study demonstrates the employment of a promising prodrug strategy using a polymeric nanomedicine for improving the vascular disrupting efficacy of colchicinoids while reducing their systemic toxicity, thereby opening the door for the application of these potent VDAs in cancer therapy.

\section{Disclosure}

This work was supported by MediTrans, an Integrated Project funded by the European Commission under the
Nanotechnologies and Nano-Sciences, Knowledge-based Multifunctional Materials and New Production Processes and Devices (NMP) program, a thematic priority of the European Commission's Sixth Framework Programme.

\section{References}

1. Hartung EF. History of the use of colchicum and related medicaments in gout. Ann Rheum Dis. 1954;13(3):190-200.

2. Terkeltaub RA. Colchicine update: 2008. Semin Arthritis Rheum. 2009; 38(6):411-419.

3. Ben-Chetrit E, Levy M. Familial Mediterranean fever. Lancet. 1998; 351(9103):659-664.

4. Ravelli RB, Gigant B, Curmi PA, et al. Insight into tubulin regulation from a complex with colchicine and a stathmin-like domain. Nature. 2004;428(6979):198-202.

5. Niel E, Scherrmann JM. Colchicine today. Joint Bone Spine. 2006;73(6): 672-678.

6. Schwartz EL. Antivascular actions of microtubule-binding drugs. Clin Cancer Res. 2009;15(8):2594-2601.

7. Bhattacharyya B, Panda D, Gupta S, Banerjee M. Anti-mitotic activity of colchicine and the structural basis for its interaction with tubulin. Med Res Rev. 2008;28(1):155-183.

8. Pasquier E, André N, Braguer D. Targeting microtubules to inhibit angiogenesis and disrupt tumour vasculature: implications for cancer treatment. Curr Cancer Drug Targets. 2007;7(6):566-581. 
9. Tozer GM, Kanthou C, Baguley BC. Disrupting tumour blood vessels. Nat Rev Cancer. 2005;5(6):423-435.

10. Kanthou C, Tozer GM. Tumour targeting by microtubuledepolymerizing vascular disrupting agents. Expert Opin Ther Targets. 2007;11(11):1443-1457.

11. Jordan MA, Wilson L. Microtubules as a target for anticancer drugs. Nat Rev Cancer. 2004;4(4):253-265.

12. Baguley BC, Holdaway KM, Thomsen LL, Zhuang L, Zwi LJ. Inhibition of growth of colon 38 adenocarcinoma by vinblastine and colchicine: evidence for a vascular mechanism. Eur $J$ Cancer. 1991;27(4):482-487.

13. Nihei Y, Suzuki M, Okano A, et al. Evaluation of antivascular and antimitotic effects of tubulin binding agents in solid tumor therapy. Jpn J Cancer Res. 1999;90(12):1387-1395.

14. Finkelstein Y, Aks SE, Hutson JR, et al. Colchicine poisoning: the dark side of an ancient drug. Clin Toxicol (Phila). 2010;48(5):407-414.

15. Dickinson M, Juneja S. Haematological toxicity of colchicine. $\mathrm{Br} J$ Haematol. 2009;146(5):465.

16. Rautio J, Kumpulainen H, Heimbach T, et al. Prodrugs: design and clinical applications. Nat Rev Drug Discov. 2008;7(3):255-270.

17. Quinn FR, Neiman Z, Beisler JA. Toxicity and quantitative structureactivity relationships of colchicines. $J$ Med Chem. 1981;24(5): 636-639.

18. Zamora JM, Pearce HL, Beck WT. Physical-chemical properties shared by compounds that modulate multidrug resistance in human leukemic cells. Mol Pharmacol. 1988;33(4):454-462.

19. Wallace SL, Omokoku B, Ertel NH. Colchicine plasma levels: implications as to pharmacology and mechanism of action. Am J Med. 1970;48(4):443-448.

20. Bagnato JD, Eilers AL, Horton RA, Grissom CB. Synthesis and characterization of a cobalamin-colchicine conjugate as a novel tumor-targeted cytotoxin. J Org Chem. 2004;69(26):8987-8996.

21. Lagnoux D, Darbre T, Schmitz ML, Reymond JL. Inhibition of mitosis by glycopeptide dendrimer conjugates of colchicine. Chemistry. 2005; 11(13):3941-3950

22. Crielaard BJ, van der Wal S, Lammers T, et al. Liposomes as carriers for colchicine-derived prodrugs: vascular disrupting nanomedicines with tailorable drug release kinetics. Eur J Pharm Sci. Epub 2011 Sep 1.

23. Parveen S, Sahoo SK. Nanomedicine: clinical applications of polyethylene glycol conjugated proteins and drugs. Clin Pharmacokinet. 2006;45(10):965-988.

24. Greenwald RB, Pendri A, Bolikal D, Gilbert CW. Highly water soluble taxol derivatives: 2 '-polyethyleneglycol esters as potential prodrugs. Bioorg Med Chem Lett. 1994;4(20):2465-2470.
25. Greenwald RB, Choe YH, McGuire J, Conover CD. Effective drug delivery by PEGylated drug conjugates. Adv Drug Deliv Rev. 2003; 55(2):217-250.

26. Denny WA. Tumor-activated prodrugs - a new approach to cancer therapy. Cancer Invest. 2004;22(4):604-619.

27. Scudiero DA, Shoemaker RH, Paull KD, et al. Evaluation of a soluble tetrazolium/formazan assay for cell growth and drug sensitivity in culture using human and other tumor cell lines. Cancer Res. 1988;48(17): $4827-4833$.

28. Wet op de dierproeven. stb. 1977, 6. BWBR0003081; Article 9.

29. European Treaty Series. 18 III 1986. ETS No. 123.

30. Brossi A, Sharma PN, Atwell L, et al. Biological effects of modified colchicines. 2. Evaluation of catecholic colchicines, colchifolines, colchicide, and novel $\mathrm{N}$-acyl- and $\mathrm{N}$-aroyldeacetylcolchicines. J Med Chem. 1983;26(10):1365-1369.

31. Nguyen TL, McGrath C, Hermone AR, et al. A common pharmacophore for a diverse set of colchicine site inhibitors using a structure-based approach. J Med Chem. 2005;48(19):6107-6116.

32. Fens MH, Hill KJ, Issa J, et al. Liposomal encapsulation enhances the antitumour efficacy of the vascular disrupting agent ZD6126 in murine B16.F10 melanoma. Br J Cancer. 2008;99(8):1256-1264.

33. Lammers T, Hennink WE, Storm G. Tumour-targeted nanomedicines: principles and practice. Br J Cancer. 2008;99(3):392-397.

34. Danquah MK, Zhang XA, Mahato RI. Extravasation of polymeric nanomedicines across tumor vasculature. Adv Drug Deliv Rev. 2011;63(8): 623-639.

35. Yamada T, Hosokawa M, Satoh T, et al. Immunohistochemistry with an antibody to human liver carboxylesterase in human brain tissues. Brain Res. 1994;658(1-2):163-167.

36. Xie M, Yang D, Liu L, Xue B, Yan B. Human and rodent carboxylesterases: Immunorelatedness, overlapping substrate specificity, differential sensitivity to serine enzyme inhibitors, and tumor-related expression. Drug Metab Dispos. 2002;30(5):541-547.

37. Redinbo MR, Potter PM. Mammalian carboxylesterases: from drug targets to protein therapeutics. Drug Discov Today. 2005;10(5):313-325.

38. Satoh T, Hosokawa M. The mammalian carboxylesterases: from molecules to functions. Annu Rev Pharmacol Toxicol. 1998;38:257-288.

39. Crow JA, Herring KL, Xie S, Borazjani A, Potter PM, Ross MK Inhibition of carboxylesterase activity of THP1 monocytes/macrophages and recombinant human carboxylesterase 1 by oxysterols and fatty acids. Biochim Biophys Acta. 2010;1801(1):31-41.
International Journal of Nanomedicine

\section{Publish your work in this journal}

The International Journal of Nanomedicine is an international, peerreviewed journal focusing on the application of nanotechnology in diagnostics, therapeutics, and drug delivery systems throughou the biomedical field. This journal is indexed on PubMed Central,

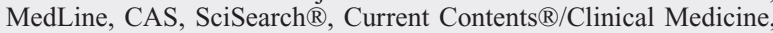

\section{Dovepress}

Journal Citation Reports/Science Edition, EMBase, Scopus and the Elsevier Bibliographic databases. The manuscript management system is completely online and includes a very quick and fair peer-review system, which is all easy to use. Visit http://www.dovepress.com/ testimonials.php to read real quotes from published authors. 